Assist. Prof. Dr. Cihat Atar ${ }^{1}$

Sakarya University, Faculty of Education

Department of English Language Teaching

Asst. Prof. Dr. Cahit Erdem ${ }^{2}$

Afyon Kocatepe University, Afyonkarahisar, Turkey

Faculty of Education, Department of English Language Teaching
Original scientific paper

UDC: 37.016

DOI: $10.5937 /$ IstrPed2002398A

\title{
A SOCIOLINGUISTIC PERSPECTIVE IN THE ANALYSIS OF ENGLISH TEXTBOOKS: DEVELOPMENT OF A CHECKLIST
}

\begin{abstract}
This study aims to suggest a checklist for teachers and researchers to analyze English as a second or foreign language textbooks from a sociolinguistic perspective. In the literature there is not a checklist or framework by which English textbooks can be evaluated considering the sociolinguistics issues raised in this study. After obtaining expert opinion and a piloting on 8 textbooks used in state schools in Turkey, a checklist consisting 6 criteria was suggested. Then, the check list was applied on the 9th grade English book ReLearn (Karamil \& Birincioglu Kaldar, 2019) used in state schools in Turkey to demonstrate how the checklist can be utilized. The findings suggest that from a sociolinguistic perspective, the book in focus occasionally conforms to the sociolinguistic concerns while it needs some qualitative improvements. Improvements in providing genuine speakers of non-native and non-standard accents of English rather than using standard accent vocalizations for the speakers that are depicted as non-natives can be a primary suggestion and at the same time, the textbook should focus on different ways of life and perspectives instead of mostly providing intercultural knowledge such as cities or historic places. Finally, the textbook should pay more attention to the linguistic ecology in Turkey and adjust its contents so as to compensate for the foreign language status of English in Turkey. Accordingly, this study contributes to the literature by providing a checklist to evaluate textbooks systematically with regard to essential sociolinguistic issues and it demonstrates the application of the checklist.
\end{abstract}

Key words: Sociolinguistic textbook evaluation, English textbooks, intercultural communicative competence, English language teaching, Turkey.

\section{Introduction}

With the globalization of the world in the recent decades and the global power the United Kingdom and then, the United States exerted throughout the world, English has become a world language and it is used for various purposes ranging from academic issues to trade and technology. As a result of this immense spread and the huge variations of users in terms of many variables such social status, political power, race, ethnicity and culture, the English used

\footnotetext{
${ }^{1}$ cihatatar@sakarya.edu.tr

2 cerdem@aku.edu.tr
} 
by these people was also affected, and different Englishes have emerged (Kachru, 2006). This idea of different Englishes clashed with the perspective which favors native speaker norms and sees the English of the inner circle as the norm.

However, according to the studies undertaken in the recent decades, the status of different Englishes has been partly recognized and acknowledged (Bayyurt, 2013 Kacru, 2006). After the social turn in the field of Applied Linguistics, many studies were undertaken to find out the social aspects of language learning in comparison to cognitive views. Studies focused on the status, power, culture and variation in language learning and the plurality of learners/users were acknowledged with the concept Englishes. Textbooks are indispensable sources in most of the contexts of language learning and in this sense, to account for the sociolinguistic issues in language teaching, it is essential to consider language textbooks as well. It is argued in this study; however, that this acknowledgement (i.e. the non-standard varieties of English) may be still at an academic level and it may lag behind in real life circumstances. Indeed, the studies in the literature suggest that native speaker norms are still seen as the base in second/foreign language learning while acquiring a native-like competence is set as the goal (Alptekin, 2002; Karakas, 2019; Newton, 2016; Sifakis \& Bayyurt, 2018). However, as Alptekin (2002) argued in his seminal work on intercultural communicative competence, attaining a native-like proficiency is utopian and unrealistic. The reason is that as a bilingual has another language in his/her mind, this will have effects on the second language in terms of all aspects ranging from grammar to phonology and syntax. Also, most learners start learning a language after the critical age and as a result, it is almost impossible for them to sound like a native. What is more, even if it is unrealistic, indeed there is not a need to attain a native-like proficiency as most of the English learners merely learn it for practical purposes such as trading and they do not use it for academic purposes. When this is supported with the fact that the number of people learning English as a second or foreign language is much larger than the native speakers, it is argued that the goal should not be set as the native-like proficiency and the standard British or American English. Rather, different social and linguistic variables should be acknowledged to have a descriptive approach rather than a prescriptive one which imposes upon the reality.

Textbooks are a significant tool in language classrooms and they are an indispensable part of teaching second and foreign languages. They not only provide the materials to be covered in the class, but also they specify the topics and aspects to be taught. In this sense, textbooks have a determining role in language teaching and learning. Lahdesmaki (2004) even argues that the strong status of textbooks defines the language itself and how it should be studied, and Arikan (2008) adds that textbooks are actually a resource book about the Western world for students. Moreover, although textbooks have some utilities such as providing a framework for teachers, ensuring coherence, providing creative teaching ideas and offering rich input (Yilmaz \& Aydin, 2015), it was found that some teachers/instructors even see them as the curriculum and they simply follow the structure provided in a textbook (Erdem \& Atar, 2018). Therefore, the quality of textbooks is of great importance and a special attention should be paid while selecting them. As Nguyen (2015) suggests, various variables should be considered in textbook evaluation and to carry out an evaluation, researchers need to take many decisions. In this sense, the goal of the curriculum and the needs of the learners are decisive factors.

Checklists are significant in that they clarify the criteria to be considered during evaluation, help the evaluator not to forget some issues, and more importantly increase the objectivity, 
reproducibility and credibility, namely reliability and validity, of the evaluation (Stufflebeam, 2000). Nguyen (2015, p. 35) argues that most of the checklist in textbook evaluation focuses on the following issues:

1. The internal content of the textbook;

2. The aims and approaches;

3. The supporting sources; and

4. The physical appearance.

As there is not a general list of criteria that is sufficient for the needs of all learners, the selection of criteria and checklists for textbook evaluation varies greatly. Textbook evaluation and selection is highly dependent upon the context and the goals, which lead to different checklist in the field. This means that there are many checklists suggested for textbooks (e.g. Alemi \& Mesbah, 2013; Litz, 2002; Nguyen, 2011, 2015); however, they mostly do not focus on sociolinguistic approaches as suggested by the extensive study on textbook undertaken by Nguyen (2015). A study undertaken by Nguyen (2011) focuses on intercultural pragmatic competence; however, the focus of the study is on authentic language use and intercultural communication, not sociolinguistic issues in general. Consequently, this paper focuses on a sociolinguistic perspective which is acknowledged as a significant issue in the field of second language acquisition (SLA) recently as argued in the previous paragraphs. Though studies evaluating textbooks mostly focus on the content of the books (Vanha, 2017), evaluation studies dwelling on a sociolinguistic perspective are lacking. Accordingly, considering the significance of textbooks in classrooms, this study has set out to form a checklist by which English language teachers and researchers can analyze a textbook in terms of sociolinguistic issues. Then, the application of the checklist on an English textbook in the Turkish context will follow to demonstrate how the checklist works. The items in this checklist and their justification will be provided below.

\section{Literature Review}

\section{Sociolinguistic Perspectives in ELT}

Sociolinguistics is a field that studies the functions and role of languages in societies. It argues for a variable account of languages in contrast to rationalist and deductive approaches which suggest that languages have certain rules. A sociolinguistic approach to languages put forward a variable approach and the use of a language is argued to depend on diverse social contexts and variables. In this sense, the sociolinguistic approach to languages is a response to prescriptive approaches. Social factors such as status, role and identity are seen as factors which lead to a variable use of languages and what is correct in languages is highly dependent upon the context (e.g. the institution, the addressor and the addressee). For example, the type of language used in a university is different than the one used in a canteen and similarly, word choice and even grammar change when we talk to the boss or an elderly person in comparison to talking to a close friend.

Alptekin (2002) initiated a reconceptualization in SLA studies by incorporating sociolinguistic perspectives into the field of Applied Linguistics more robustly and thus a variable approach to the field was underlined. Alptekin (2002) argues that achieving communicative competence and attaining native-like proficiency is utopic. Accordingly, he suggests improving intercultural communicative competence (ICC). As for McKay's study (2011), it sheds light on how to incorporate the findings of English as a Lingua Franca (ELF) and English as an International 
Language (EIL) studies into the teaching of English. These two studies are seminal works in sociolinguistic perspectives in SLA. Alptekin's (2002) study made a break through by challenging the dominant communicative competence approach with a new concept, which is the intercultural communicative competence. He also argued that language is situated within the society and thus, it is immensely affected by social factors. As for the other seminal work, McKay (2011), it is one of the pioneering studies which specially focused on the implications of Sociolinguistics on language teaching. Accordingly, the authors of this study analyzed the implications provided by these two studies and formed the framework that consists of 6 criteria mainly depending on these studies. The goal of the checklist is to assess books in accordance with the requirements and needs of speakers in the global age after the social turn (Firth \& Wagner, 2007) in SLA studies. Accordingly, considering the goal of this study, the checklist was developed and via piloting ( 8 books that are used in public schools were checked to see if the points in the checklist are applicable) and expert opinion was obtained. In the following section, the checklist will be introduced in a point by point fashion and the justifications will be provided.

\section{The 6 criteria for sociolinguistic textbook evaluation}

1. Provide non-native (e.g. Indian English) and non-standard (e.g. The Birmingham accent or Geordie) accents/varieties of English.

This item acknowledges the fact that there are Englishes rather than a single English. The spread of English culminated in different non-native varieties in addition to native varieties. This criterion is essential as the number of non-native speakers outnumber the speakers that speak a native variety (Cook, 2008). Today, non-native to non-native interaction has become very common and some bilinguals do not even talk to a native speaker at all. As for the native varieties, communicative competence traditionally depends on the standard accents. However, standard accents are used by a limited number of people even among the native speakers. For instance, RP is used by only the minority of British English speakers (Cook, 2008). From a pedagogical perspective, it means that this situation should be considered by language policy makers and course books, as the standard accents taught in lessons represent only a minority in real life. Hence, textbooks should provide different accents and varieties to expose students to different varieties, which will increase their awareness of the different Englishes and their ability to understand more speakers of both non-native and non-standard accents/varieties.

\section{Provide native-non-native and non-native-non-native instances of interaction}

The use of native speakers of English as the model in textbooks has been the norm throughout the world until quite recently. On the other hand, there is relatively little attention given to encourage the students to become bilinguals and users of English (Cook, 2008) at different competence levels with their own accent rather than having a native-like proficiency. This case can have some detrimental effects on students with regard to dealing with anxiety. The reason is that attaining a native-like proficiency is utopic (Alptekin, 2002) and indeed, there is not a need for that as most of the people around the world learn it for practical purposes (doing trade, selling souvenirs to tourist and so on). In this sense, aiming for a native-like proficiency will prove to be too difficult for the learners, which will ultimately lead to confidence and motivation problems as the goal is too unrealistic.

As for some relevant studies, Sener (2014) researched the willingness of ELT students at a state university in the Turkish context regarding communicating in English in and out of the 
classroom. The findings suggested that the most of them had a positive attitude towards English and the culture of English speaking countries. The participants who perceived themselves as competent and confident in communication were more eager to initiate communication while most of the participants did not show any willingness to communicate with their teachers because their teachers seemed to be critical and low-tolerant to their mistakes. This study suggests that focusing on a standard accent and an error-free native like proficiency may lower students' willingness and motivation to use English.

Therefore, this point argues that the aim of language teaching and textbooks should be to make their students successful bilinguals with their own accent (especially until they are really proficient or unless their needs and/or goals require a native-like proficiency). As argued in (Bayyurt, 2006) as well, Turkish EFL teachers' perceptions revealed the predominance of traditional EFL practices while finding little awareness of the changing status of English. This suggests that there is still not sufficient awareness of the status of non-standard and nonnative varieties of English. Accordingly, the textbooks should set native speakers as the norm, who are the only competent users of English. Instances of interaction between native and non-native, in which non-natives can aptly communicate, should be provided. Also, considering the ELF status of English, non-native to non-native instances should also be presented, which is in fact a more realistic scenario in the world as most of the speakers of English communicate with only non-natives (Alptekin, 2002). It should also be noted here that this point is different than the first one in that there can be instances of non-standard and non-native accents in a textbook, but in these instances, typically foreigners talk to natives. However, in today's world a significant part of English communication takes part between non-natives (Cook, 2008).

\section{Include examples of successful bilinguals}

This criterion seems similar to the $2 \mathrm{n}^{\mathrm{d}}$ criteria; however, it specifically focuses on the prospect of being a successful learner. Most of the learners see themselves as incompetent, and textbooks usually depict learners in incompetent roles. As Cook (2008) observes, the characters that are supposedly L2 users fall into two main categories in textbooks: tourists and students who are not very good at functioning in the society in terms of communication while native speakers are shown as competent people. On the other hand, Kramsch (1997) rightfully suggests that language learners are destined to be bilinguals as they can never become native speakers, which shows that the goal of language teaching should be to become a successful bilingual. Therefore, it is significant for presenting students a chance to see how people from different backgrounds use English to achieve mutual understanding. In order to motivate and set an achievable goal, students should be provided with instances in which language learners are people who use language to realize their goals in life. In this sense, providing instances of successful bilinguals not only makes learning more realistic and effective (Matsumoto, 2011) but also more motivating and relevant. Especially, including instances of real-life interactions which is preferably outside the classroom will be more effective in comparison to stereotypical and mechanical dialogs as models.

\section{Promote intercultural communicative competence}

Communicative approaches is almost the norm in English language teaching and attaining communicative competence is the ultimate goal. The idea of communicative competence sets the norms of British and American culture (i.e. the original (!) native speakers) as the target and standard norm for all the learners of English, ignoring various variables such as the context, and the needs and goals of the learners. (Cetinavci, 2012). However, this ignores 
many social factors especially the realm of the outer and expanding circles. This entails the view that the learners of English abandon their culture and identity and stick to the native norms just because they use English, which is called by Byram (1997, p.12) as "linguistic schizophrenia". On the other hand, especially thanks to the sociolinguistic studies that acknowledge the variables in learners, recently, it is argued in the literature that the cultural contents of English should not be restricted to native speaker norms (Bayyurt, 2013; Dang \& Seals, 2016; McKay, 2003; Newton, 2016). Learners' local culture and other countries' cultures must be provided in the learning process to increase their awareness about intercultural differences. Thanks to the development of intercultural communicative competence ICC, it is possible to have students that are able to deal with communication breakdowns, real-life crises, and mostly-faced problems (Alptekin, 2002). In the Turkish context, the integration of culture into classroom settings is still in infancy and studies are needed (Bayyurt, 2013). For instance, in a study undertaken by Atay et al. (2009), it was shown that foreign language teachers mainly aimed to teach English for practical issues and they did not focus on intercultural aspects of language learning.

Including both local and global aspects of people can provide huge benefits in increasing the involvement of students in the classroom (Lessard-Clouston, 1997). McKay (2003) also argues that local expectations of teachers and learners' roles in the teaching and learning of English should be taken into consideration. Global issues may offer interesting subjects to students and at the same time learning about the target culture improves their learning. At the same time, the use of local issues and native culture may prevent students from feeling alienated altogether. Hence, it may be argued that teachers' having knowledge about local and global issues may be very motivating for learners and it can set an example.

So, it may be suggested here that teachers, especially in Turkey, do not have a sufficient level of intercultural awareness, which is possibly the same case in textbooks. As Bayyurt (2013) suggests, promoting ICC can be a way to change the attitudes of learners and teachers towards non-standard varieties. Promoting ICC can also improve understanding and acknowledging local culture as well different cultures, which can enhance interaction in a second/foreign language as well. Consequently, textbooks, as the integral element of language teaching, can help achieve this goal.

\section{Consider the linguistic ecology of learners and their L1 (or other languages as well)}

This item refers to what kinds of languages are used in the current country of the students and what is the status of the target language. Linguistic ecology hints at the status of language in a certain country. This means that the role of English in the particular geographical and social context is a significant factor in the teaching of English in a country, and the status of the target language in relation to the mother tongues of the students is of an important issue. For instance, whether the target language is a second or foreign language make a huge difference. In the foreign language case, the target language does not have a social status and it is not commonly used in daily life. In Turkey, for example, English does not have a status in the legislation and it is not used in the daily lives of the Turkish people except for restricted cases such as touristic places. In this sense, the learners may feel alienated with the language learning as the target language does not have an immediate effect or benefit in their live.

Moreover, countries may have local lingua francas (e.g. Turkish in Turkey), but due to standardization, this may put local accents or other languages in a country in a less favourable 
position. This affects the role of local languages as they are not given any significance (McKay, 2011). In this sense, it is better to consider the linguistic ecology of the learners and maybe including some local features or lexical items from these languages may help the speakers of these languages to associate with the English language and keep their identity. Then, in case of English as a foreign language, the use of the L1 (or other languages) of students may be used in the textbooks to form a link between the two. In this way, the target language may mean something for the learners as it links their languages to the target language and the status of the local varieties may be acknowledged without staying in the shadow of English completely.

6. Alter the case of English learning among only the elites of the country

This item is mainly about the financial aspects of English teaching/learning. As Alptekin (2002) argues, the monetary aspects of English leads to gatekeeping. Therefore, learning English is expensive in many countries and even if a student is good at learning English, s/he might not have the chance to learn English. The elites have the chance to go to private schools that teaches English well or even teach in English. This, in the long run, strengthens the social inequality even more as knowing English is an essential must for getting a better job and position in a society or having the prospect of working internationally. In this sense, we suggest here that textbooks that are available to the average people is of utmost significance to contribute to the society. This is essential in that there is a reflexive relationship between societies and languages. So, to change language teaching, the social structures and the status of the people must be considered. One way to achieve this may be providing books for free to the public. However, it must be noted that these books must be of good quality. Otherwise, the rich will still have access to better books with money. Accordingly, if the freely available textbooks are not good, it will still be difficult for the masses to learn English effectively and to reverse the social imbalance regarding the benefits of learning English.

Considering the literature review, the research questions of this study are formulated as follows:

What should be the items of a checklist to evaluate language textbooks from a sociolinguistic perspective?

To what extent does the 9th grade textbook ReLearn (Karamil \& Birincioglu Kaldar, 2019) used in state schools in Turkey conform to the sociolinguistic criteria suggested in the checklist in this study?

\section{Methodology}

This study involves two phases: (1) development of a language textbook evaluation checklist focusing on a sociolinguistics perspective, and (2) evaluating an English textbook by using the developed instrument to serve as a model for the instrument's usage. The first phase includes instrument development and the second phase includes document analysis.

\subsection{Development of the checklist}

Stufflebeam (2000, p. 2-3) offers an extensive set of guidelines to develop evaluation checklists. He recommends 12 steps in this process: "(1) Focus the checklist task, (2) Make a candidate list of checkpoints, (3) Classify and sort the checkpoints, (4) Define and flesh out the categories, (5) Determine the order of categories, (6) Obtain initial reviews of the checklist, (7) Revise the checklist, (8) Delineate and format the checklist to serve the intended 
use, (9) Evaluate the checklist, (10) Finalize the checklist, (11) Apply and disseminate the checklist, (12) Periodically review and revise the checklist". This study employs these guidelines to ensure reliability and validity in developing the coursebook evaluation rubric.

The analysis was undertaken in 2019-2020 and the criteria in the rubric was chosen after an extensive literature review in the field, especially focusing on the eminent researchers in this field such as Alptekin (2002) and McKay (2011) and a list of criteria were prepared as suggested in step 2 above. Then, they were sorted and classified in a way that they focus on one clear issue and they were ordered from main issues such as the role of English as a lingua franca. Having identified the 7 criteria, the author sent it for piloting and expert opinion and feedback was received from professionals in the field. In the piloting, 8 textbooks in state schools in Turkey were selected and whether it worked was tested. According to the results of piloting and expert opinion (which will be provided in detail in the findings section), the checklist was amended (to six criteria) and finalized.

\subsection{Evaluation of an English textbook: Document Analysis}

The book that is analyzed to demonstrate how the checklist works is the $9^{\text {th }}$ grade English textbook ReLearn (Karamil \& Birincioglu Kaldar, 2019) used in state schools in Turkey. In Turkey, the state provides books for free in schools until the university. This specific book was chosen for the study as the researchers agreed that very low level books might not include sociolinguistic issues naturally (McKay, 2011) as their low proficiency level requires the course to be focused on relatively simpler issues. Accordingly, the researchers considered high school textbooks and the $9^{\text {th }}$ grade was considered as appropriate as the first year of high school. The textbook in focus is based on four skills and it aims to create an interactive language learning atmosphere. Rather than focusing on grammatical issues, it is designed to provide language practice in different contexts and for various functions. The book was approved by Turkish Ministry of National Education for use in state high schools in the $9^{\text {th }}$ grade.

Document Analysis technique is used in the evaluation of the textbook. Document Analysis involves examination of a document to come up with conclusions regarding the social conditions, which embodies a variety of approaches such as Content Analysis, Interpretive Approach and Critical Approach (Bloor \& Wood, 2006). This study adopts an Interpretive Approach in Document Analysis. Interpretive approach is interested in the meaning in the content (Jupp \& Norris, 1993). The meaning assigned by textbook authors, teachers and students are explored in the current study with a sociolinguistic perspective.

\section{Findings and Discussion}

\subsection{Findings and discussion regarding the development of the checklist}

To develop the checklist for evaluating language textbook with a sociolinguistic perspective, the guidelines offered by Stufflebeam (2000) was followed. Considering the works of Alptekin (2002) and McKay (2011) in addition to various relevant studies, seven criteria were detected initially. To validate the checklist, a pilot study on 8 books used in public schools in Turkey was undertaken and the checklist was sent to expert opinion.

The analysis of the piloting and expert opinion showed that in general, the points were applicable and clear, but the researchers recognized that some points do not provide black 
and white conclusions. For example, for an item a few instances were detected in the book, but whether it was sufficient to say that the book realizes that issue was questionable. Hence, the category 'partly' was added in addition to 'yes' and 'no'. Further distinctions could be added to such as "never, rarely, often" and so on; however, in order to focus on qualitative aspects, this was avoided as it could make the check-list too categorical. In other words, we aimed to keep the qualitative perspective of the checklist so that it can be used to have a holistic understanding of a textbook rather than turning it into a Likert scale.

A major change was also made in the items after the piloting. The initial checklist had 7 criteria. However, after the piloting, it was observed that the $4^{\text {th }}$ (promoting ICC) and the $5^{\text {th }}$ (promoting global and local learning at the same time?) were overlapping in nature. ICC deals with the awareness regarding different cultures in addition to the role of local settings of learners. In this sense, it covers the scope of the $5^{\text {th }}$ criterion as a result, it was discarded.

As for the expert opinion, the criteria that were selected were approved as appropriate for a sociolinguistic perspective and some minor changes on wording of the criteria were made. Also, it was seen that the first and the third criteria might be confusing. So, in the explanation of the criteria in the literature review part, the difference between the two criteria was clarified. Finally, thanks to the expert opinion, it was found that the terms non-native and nonstandard (in the $1^{\text {st }}$ item) can be confusing for especially practitioners as there is only a nuance between the two. Therefore, in parenthesis some instances (e.g. Indian English and the Birmingham accent) were mentioned to clarify these terms. Considering all these issues, the checklist was finalized as follows:

Table 1. The Sociolinguistic Evaluation Checklist for English Textbooks

\begin{tabular}{|c|c|c|c|}
\hline THE CRITERIA & Ass & sment & \\
\hline Does the course book ... & Yes & Partly & No \\
\hline $\begin{array}{l}\text { 1. provide non-native (e.g. Indian English) and non-standard (e.g. The Birmingham } \\
\text { accent or Geordie) accents/varieties of English. }\end{array}$ & & & \\
\hline 2. provide native-non-native and non-native-non-native instances of interaction? & & & \\
\hline 3. include examples of successful bilinguals? & & & \\
\hline 4. promote intercultural communicative competence? & & & \\
\hline $\begin{array}{l}\text { 5. consider the linguistic ecology of learners and their L1 (or other languages as } \\
\text { well)? }\end{array}$ & & & \\
\hline 6. alter the case of English learning among only the elites of the country? & & & \\
\hline
\end{tabular}

\subsection{Findings and discussion regarding application of the rubric to a language textbook}

The final form of the rubric was applied to the textbook introduced above to show the operationalization of the instrument. The summary of the findings can be seen in Table 2 below. Then, the findings of the evaluation will be presented and discussed in detail below in line with the order of the criteria in the rubric.

Table 2. The Results of ReLearn with regard to the sociolinguistic textbook evaluation checklist

\begin{tabular}{|c|c|c|c|}
\hline THE CRITERIA & Asse & sment & \\
\hline Does the course book ... & Yes & Partly & No \\
\hline $\begin{array}{l}\text { 1. provide non-native (e.g. Indian English) and non-standard (e.g. The Birmingham } \\
\text { accent or Geordie) accents/varieties of English. }\end{array}$ & & & $X$ \\
\hline 2. provide native-non-native and non-native-non-native instances of interaction? & & $\mathrm{X}$ & \\
\hline 3. include examples of successful bilinguals? & & $\mathrm{X}$ & \\
\hline 4. promote intercultural communicative competence? & & $\mathrm{X}$ & \\
\hline
\end{tabular}


5. consider the linguistic ecology of learners and their L1 (or other languages as well)?

6. alter the case of English learning among only the elites of the country?

3.2.1. provide non-native (e.g. Indian English) and non-standard (e.g. The Birmingham accent or Geordie) accents/varieties of English?

The book provides international contexts and some of them are mentioned in the themes as World Heritage (Theme 7) and Studying Abroad (Theme 1). The book also includes characters who are supposedly non-native speakers (e.g. Ali on page 12, Haruki on page 15 Miki and Sakiko as in Figure 1), but according to our analysis of the book, we could not get any hint about speakers who speak a non-standard dialect.

\section{Listening Time}

20. Answer: Do you like going shopping alone or with someone?

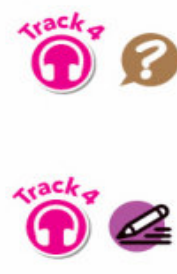

21. Listen to the dialogue and answer: Do Miki and Sakiko often meet?

22. Listen again and complete the missing parts.

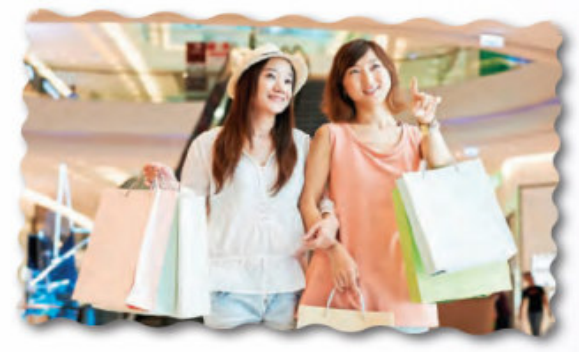

Figure 1. Miki and Sakiko (p. 19)

In this sense, the book provides a case in which the focus is not solely on native speakers. However, when the audio recordings of the textbook were checked, it was observed that the language used in the textbook is American and British standard English. It was seen that the non-native speakers also speak with a standard accent although they are portrayed as international students (E.g. Track 2). These people may simply be very advanced learners, which is why they have a native-like accent; however, this case is observed in other cases as well. Hence, the students are not presented with a chance to be exposed to non-native and non-standard accents/varieties of English.

As Alptekin (2002, p.61) argued, the lingua franca status of English makes it clear that most of the world needs and uses English for pragmatic issues such as professional encounters, academic studies and trading. This means that most of the time communication in English requires and will increasingly require non-native to non-native speaker interactions. Accordingly, textbooks should pay attention to the Lingua Franca position of English and act accordingly.

\subsection{2. provide native-non-native and non-native-non-native instances of interaction?}

The book presents these kinds of interaction. There are people from different nationalities and cultural backgrounds (Figure 1 and 2). Moreover, in Theme 5 Inspirational People, there are people named Zeynep, Merve, and Benjamin, who talk about two Turkish celebrities. It is observed that there is both non-native to native and non-native to non-native interaction. In 
this sense, it exemplifies native-non-native and non-native to non-native interaction as suggested by McKay (2011). However, as also argued in the previous point, as far as observed in the analysis, these people speak like natives and their proficiency is almost perfect in the given extracts in the textbook. In this sense, it can be argued that the interaction actually looks as if it is between native speakers although their names and photos may reflect a nonnative speaker.

\section{Listening Time}

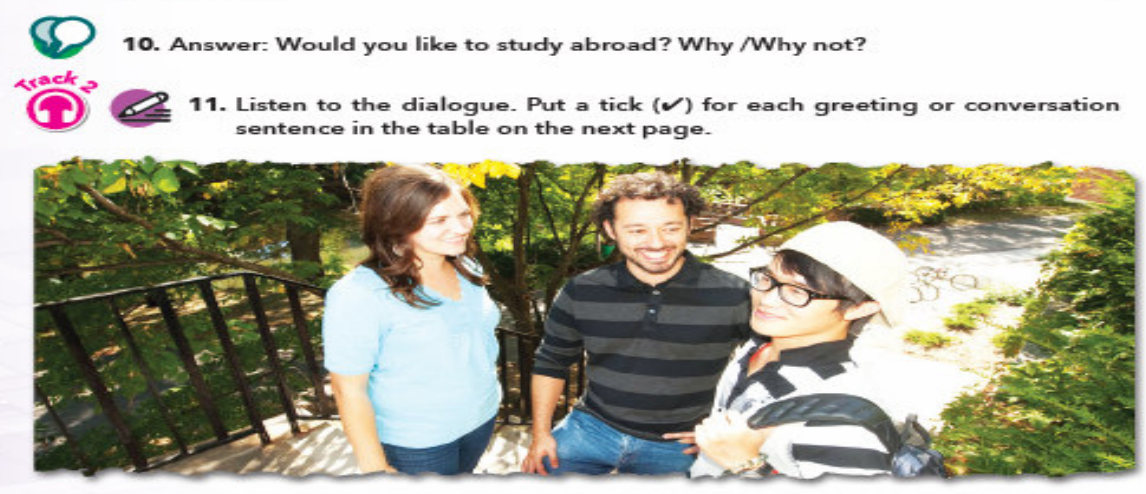

Figure 2. International Students

\subsection{3. include examples of successful bilinguals?}

The book provides several instances of successful bilinguals (e.g. Mrs. Rashid and Peter). It presents people from different ethnic backgrounds who can communicate well. However, these people do not seem to be genuine bilinguals and in the recordings (e.g. Track 17 in the book), they sound quite native. In this sense, it may be argued that the book may fail in setting successful examples for the learners as it is difficult to believe that these speakers are genuine bilinguals. Then, in another instance, there is an international student named Haruki (Figure 2). This Asian student; however, speaks with a standard accent, which is of course possible, but it does not seem realistic as an international student will probably have a varying degree of an accent. In this sense, the book is very good at providing instances of successful bilinguals and many instances of speaker from many different backgrounds (E.g. Asian, Turkish and African people throughout the textbook) are depicted as communicating smoothly in the textbook. Yet, considering the fact that learners are destined to be bilinguals, the point is to be a successful bilingual because they can never become native speakers of the language (Kramsch, 1997). Therefore, providing instances of successful bilinguals not only makes learning more realistic and effective (Matsumoto, 2011), it would be beneficial to have genuine bilinguals in the recordings, which is in parallel with the non-native people presented in the photos.

\subsection{4. promote intercultural communicative competence?}

There are some intercultural themes in the textbook such as Bridging Cultures (Theme 6), World Heritage (Theme 7) and Studying Abroad (Theme 1). In these units, instances of cultural elements from Turkish, English and other cultures are provided. Especially, starting the book with the first theme (i.e. Studying Abroad) can set a motivating atmosphere for students and it 
can expose students to different cultures and different ways of life. The textbook also mentions significant places such as Berlin and Venice and it provides instances of meals and foods in different cultures (Figure 3).

\section{Speaking Time}

17. Work in pairs. Use the menu below and the clues on the next page to order food in a restaurant.

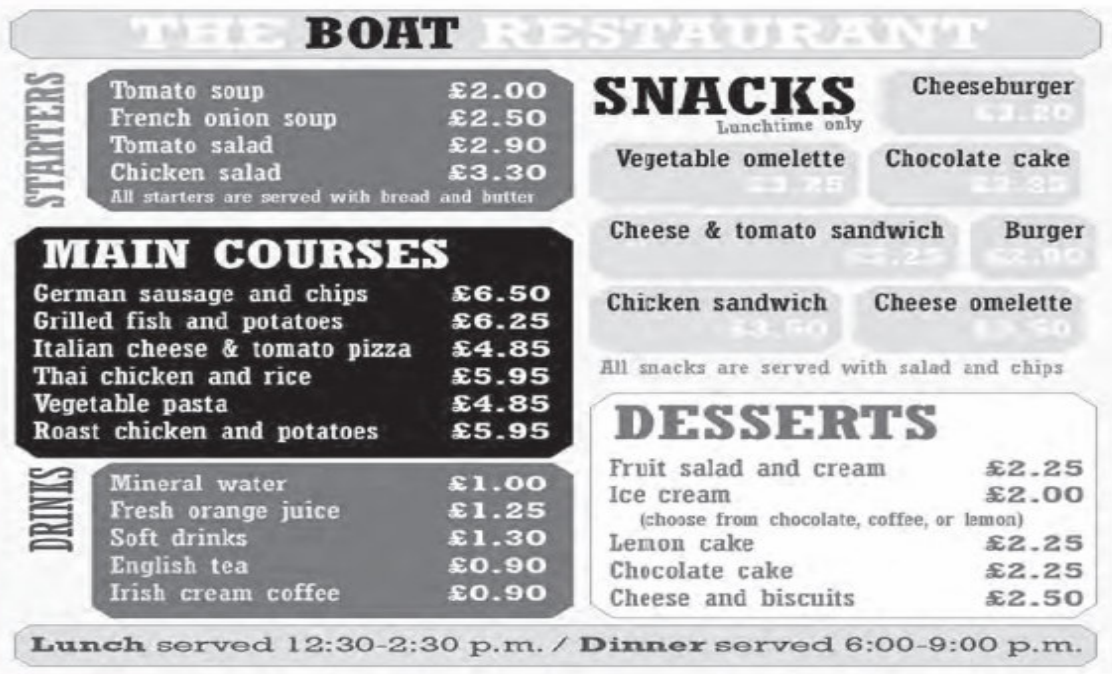

Figure 3. Meals

Moreover, the textbook exemplifies some instances of politeness (i.e. rejection), which can contribute their intercultural awareness regarding directness and indirectness (Figure 4). Finally, the book provides some idioms from English. Idioms can be a good candidate as representatives of the target culture as they can reflect the world view of the speakers of a language (Figure 5). Considering these, it may be argued here that the textbook provides instances of both local and international cultural elements, which may increase the awareness of students about differences in other cultures. As awareness is an initial step in understanding and respecting other cultures, the textbook may be argued to contribute to the development of intercultural communicative competence. 
14. Listen to the dialogue and reorder the conversation.
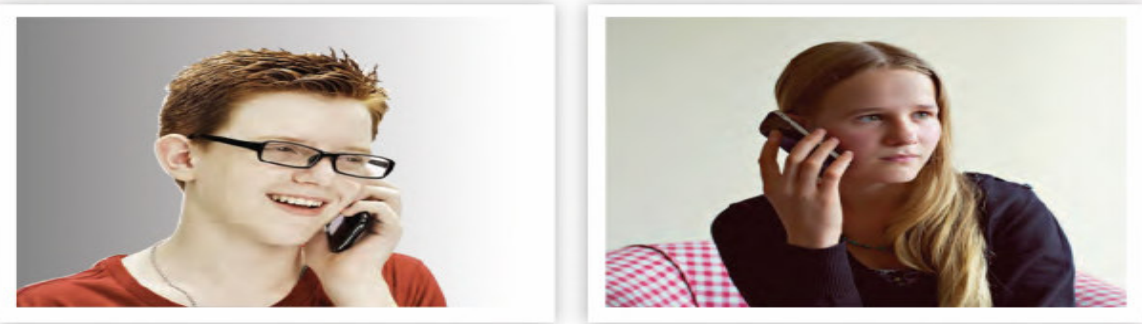

( 1 ) Hello Joy! There's a good film on at the Star Cinema. Let's see it tonight.

( ) Nightmare on Elm Street.

( ) Comedy films are not very me. Why don't we watch lce Age 7, then?

( ) OK. How about seeing it tomorrow afternoon?

( 8 ) l'd love to watch it with you. When?

( ) See you.

Figure 4. Politeness

\section{IdiomTime}

Coleb: acelebity

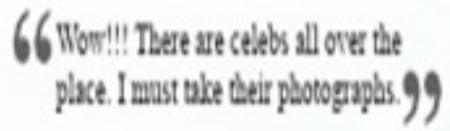

man of his word / woman of her word:

A man/woman who tells the truth and keeps promises

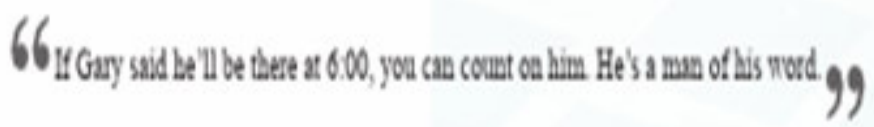

Figure 5. English Idioms

The textbook also supplies instances from the local culture (i.e. Turkish culture and heritage) and it seems that it successfully incorporates them into different units (e.g. see Figure 6 and 7). Localizing educational contexts is one of the best ways to motivate students and improve their language learning (Alptekin, 2002); however, learners should be prepared to be an international citizen at the same time. Focusing on the native norms definitely has serious flaws, but using too much local content can also hamper language learning as the students will not be able to learn about intercultural issues which are essential in learning and communicating in a language. 


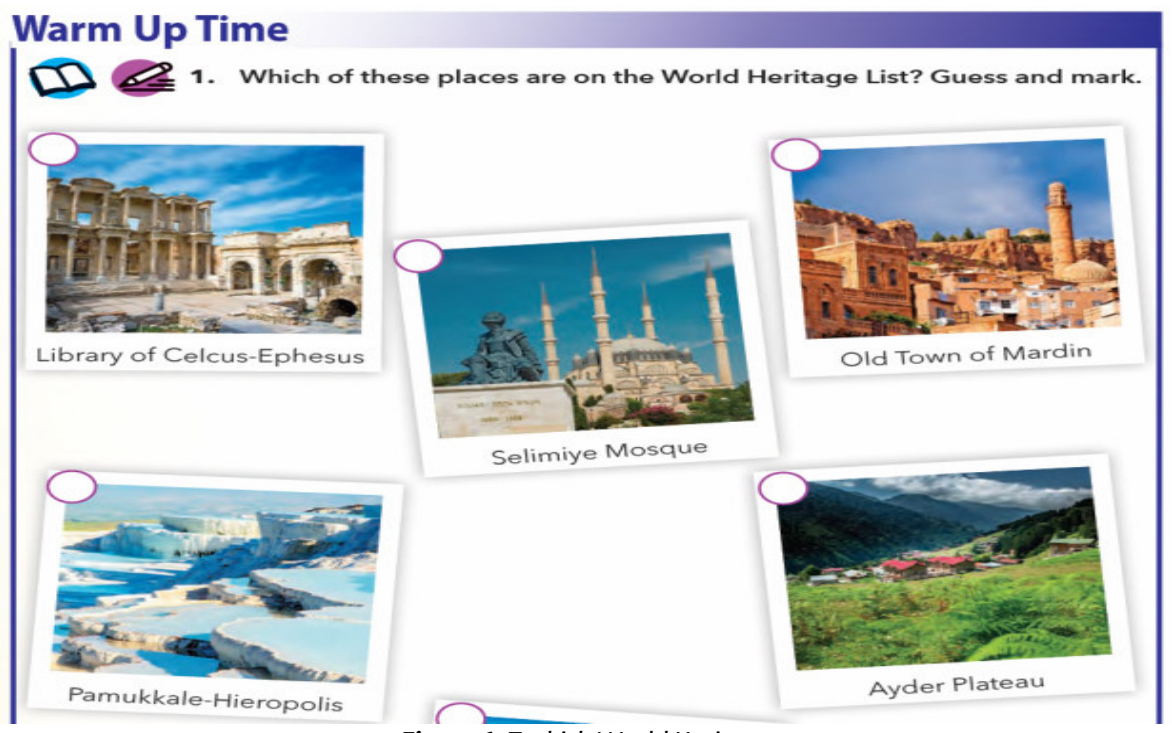

Figure 6. Turkish World Heritage

One issue here that the textbook overwhelmingly focuses of the Turkish and English cultures, which is quite understandable. However, there are only few references to other cultures (e.g. Venice and Berlin). Considering the fact that English has become a lingua franca and that the non-native speakers outnumber native speakers (Jenkins, 2009), instances from other cultures may also be included. One of underlying effects of communicative competence, which sets the norms of British and American culture as the target and standard norms for all learners of English, is ignoring the context and the needs of learners (Cetinavci, 2012). Especially the realm of the outer and expanding circles are ignored (Byram, 1997; Phillipson, 1992), which seems to be the case in this textbook. Also, as Bektas-Cetinkaya and Borkan (2012) and Bayyurt (2013) suggests, including cultural elements in the English language curriculum helps learners to understand new concepts and it enables the language use in a context.

To summarize the observations regarding this criterion, it can be argued that the textbook provides satisfactory amount of materials regarding promoting global and local learning in accordance with the suggestions of the checklist and thus the studies of Alptekin (2002) and McKay (2013). However, it should also be noted that although the textbook seems to be sufficient in this criterion by including instances of cultural elements both locally and also globally, it may be suggested that cultural elements from other non-standard and non-native varieties of English should be included more.

\subsection{5. consider the linguistic ecology of learners and their L1 (or L2 and other as well)?}

Linguistic ecology deals with the status of languages in a certain country. So, the L1 of the students and the status of English in that country should be considered in a textbook (McKay, 2011). In this textbook, learners' L1 (i.e. Turkish) does not seem to be taken into consideration except for the cases in which some local names for celebrations, city names, and famous people from Turkey are mentioned (Figure 7). It should be noted that presenting scientists like 
Nobel winner Aziz Sancar can motivate the students as they can come by material about Aziz Sancar that is in English.

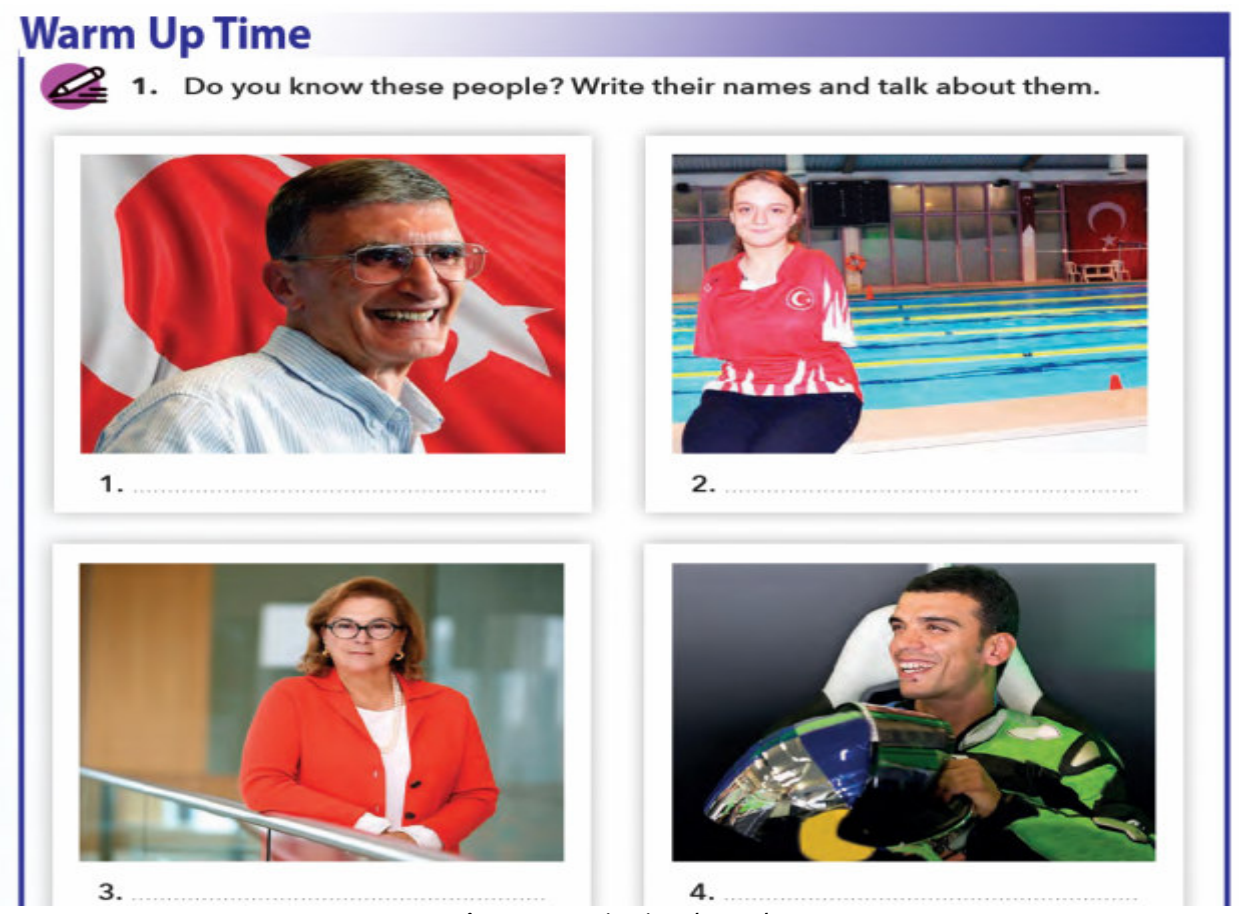

Figure 7. Inspirational People

Also, the book in general does not consider the fact that that English learners in Turkey rarely has a chance to speak English out of the classroom. One suggestion could be to provide the contexts in Turkey where English is used. Students can be assigned homework and out of classroom activities in which they need to use English to carry out a task in Turkey. It could be touristic places or cosmopolitan cities like istanbul and the students could be provided with the instances where English is a part of the daily life.

\subsection{6. alter the case of English learning among only the elites of the country?}

As mentioned in the methodology part, the textbook is distributed for free in public schools and education is also free in public schools in Turkey. When the textbook is assessed, it can be suggested that it focuses on four skills. Consequently, it can be argued that the book can respond to the recent developments in the field and the researchers of this study think that it can contribute to communicative competence thanks to various activities that provides students with a chance for practice and production in addition to competence. In this sense, considering the fact that the textbook is free and that it also satisfies the requirements of a modern English language teaching, it improves the case of English learning in Turkey. Students from low income or social groups can have the chance to learn English for free thanks to this book. However, as argued throughout this study, another significant point is the sociolinguistic issues. As argued in the literature (Alptekin, 2002; Bayyurt, 2013; McKay, 2013; Newton, 2006), sociolinguistic issues should also be addressed to align the teaching of 
English with the requirements and realm of the modern world. In this sense, if the textbook in focus may be improved in some of the issues discussed in this paper, it could be a great opportunity to challenge the learning and teaching of English among the elites of a country as this textbook is freely accessible to the students and people in Turkey.

Yet, it should still be kept in mind that, as Dogancay-Aktuna and Kiziltepe (2005) argues, English is the most common foreign language in Turkey and it provides a status to its learners as it is associated with modernization and elitism among the middle class educated people and people with a high socioeconomic status. Upper-middle or higher level classes can send their children to private schools or colleges which provide better and more English courses (Kirkgoz, 2007), which can increase the gap between different classes in the society. Hence, it is really significant to ensure that the textbooks provided by the state are of very high quality, which includes paying attention to sociolinguistic issues as well.

\section{Conclusion}

This study aims to develop a rubric by which practitioners or academicians can evaluate whether a language textbook is coherent with the sociolinguistic issues. The implication provided by two eminent researchers in the field of Sociolinguistics were synthesized in addition to the studies of many other researchers and a draft checklist was prepared. Then, a piloting was undertaken on 8 books that are used in public schools and expert opinions were utilized to check the reliability and validity of the checklist. Considering the piloting and expert opinion, some relevant changes were made, and it was finalized. After that, the rubric was applied in a textbook that was used in government schools to demonstrate the checklist. The results showed that from a sociolinguistic perspective, the textbook on average conforms to the sociolinguistic concerns while it needs some qualitative improvements. The textbook provides some instances of non-native speakers; however, they use perfect standard accents as if they are natives. Moreover, the textbook should focus on different ways of life and perspectives instead of mostly providing intercultural knowledge such as cities of historic places. Finally, the textbook should pay more attention to the linguistic ecology in Turkey and adjust its contents so as to compensate for the foreign language status of English in Turkey. Accordingly, this study has contributed to the literature by creating a checklist to evaluate language textbooks systematically according to sociolinguistic issues. It has also demonstrated the application of the checklist on the textbook ReLearn.

As for the limitations, as the textbook is a qualitative one, it does not intend to provide descriptive results. Rather, it focuses on providing the details about the criteria provided in the rubric and it has no goals or claims of making generalizations or providing a statistic of compliance to sociolinguistic issues. Similarly, the results obtained from this checklist regarding a textbook does not entail a general evaluation about that book. This checklist gives an idea about only sociolinguistic issues. In this sense, the fact that a textbook has a relatively negative result from this checklist does not mean that that textbook is not qualified enough in general. However, still we underline the fact that considering the recent literature, it is essential that textbooks pay attention to sociolinguistic issues.

As for the future implications, the checklist provided in this study may be used by practitioners, academicians and publishers alike. It can be used to analyze the other textbooks used in government and/or private schools in Turkey or abroad as this study analyzed only the 9th grade textbook ReLearn (Karamil \& Birincioglu Kaldar, 2019) in detail. Teachers can use it 
to check whether a textbook they plan to use pays attention to sociolinguistic issues especially considering the sociolinguistic realms in their country. As for academicians, this textbook can be used by master's students or others to analyze and assess language textbooks and identify some points to be improved. Finally, publishers or English language book authors may also use this rubric to understand if their book is in line with the sociolinguistic matters and the status of English as a lingua franca or international language.

\section{References}

Alemi, M. \& Mesbah, Z., (2013). Textbook evaluation based on the ACTFL standards: The case study of Top Notch series. The Iranian EFL Journal, 9, 162-71.

Alptekin, C. (2002). Towards intercultural communicative competence in ELT.ELT Journal, 56(1), 57-64.

Arıkan, A. (2008). Topics of reading passages in ELT coursebooks: What do our students really need? The Reading Matrix, (2), 70-85.

Atay, D., Kurt, G., Camlıbel, Z., Ersin, P. \& Kaslioglu, O. (2009). The role of intercultural competence in foreign language teaching. Inonu University Journal of the Faculty of Education, 10(3), 123-135.

Bayyurt, Y. (2006). Non-native English language teachers' perspective on culture in English as a

Foreign Language classrooms. Teacher Development, 10(2), 233-247.

Bayyurt, Y. (2013). Current perspectives on sociolinguistics and English language education. The Journal of Language Learning and Teaching, 3(1), 69-78.

Bektas-Cetinkaya, Y. \& Borkan, B. (2012). Intercultural Communicative Competence of Preservice Language Teachers in Turkey. In Y. Bayyurt \& Y. Bektas-Cetinkaya (Eds.), Research Perspectives on Teaching and Learning English in Turkey: Policies and Practices (pp. 107-120). Frankfurt: Peter Lang.

Bloor, M. \& Wood, F. (2006). Keywords in qualitative methods: A vocabulary of research concepts. London: Sage Publications.

Byram, M. (1997). Teaching and assessing intercultural communicative competence. Clevedon, England: Multilingual Matters.

Cook, V. (2008). Second Language Learning and Language Teaching (Fourth Edition). London: Hodder Education.

Cetinavci, U. R. (2012). Intercultural communicative competence in ELT. Social and Behavioral Sciences, 46(1), 3445-3449.

Dang, T. C. T. \& Seals, C. (2016). An Evaluation of Primary English Textbooks in Vietnam: A Sociolinguistic Perspective. TESOL Journal, 9(1), 93-113.

Dogancay-Aktuna, S. \& Kiziltepe, Z. (2005). English in Turkey. World Englishes 24(2), $253-265$.

Erdem, C. \& Atar, C. (2018). Yuksekogretim Duzeyindeki Zorunlu Ingilizce Derslerinin Ogretim Gorevlisi Goruslerine Gore Degerlendirilmesi [An Evaluation of the compulsory English lessons in Higher Education according to Instructors' views]. ICPESS-VENICE, pp. 1-14.. 28-30 June 2018 Venice-ITALY.

Firth, A., \& Wagner, J. (2007). Second/Foreign language learning as a social accomplishment: Elaborations on a 'reconceptualised' SLA. The Modern Language Journal, 91(1), 800-819.

Jenkins, J. (2006). Current perspectives on teaching world Englishes and English as a lingua franca. TESOL quarterly, 40(1), 157-181.

Jupp, V. \& Norris, C. (1993). Traditions in documentary analysis. In M. Hammersley (Ed.) Social research: Philosophy, politics and practice. London: Sage Publications. 
Kachru, B. B. (2006). Standards, codification and sociolinguistic realism: The English language in the outer circle. In K. Bolton \& B. B. Kachru (Eds.), World Englishes: Critical concepts in linguistics. Abingdon, England: Routledge.

Karakas, A. (2019). Preferred English Accent and Pronunciation of Trainee Teachers and Its Relation to Language Ideologies. PASAA, 58, 264-294.

Karamil, L. \& Birincioglu Kaldar, E. (2019). High School Relearn Grade 9. Ankara: Pasifik Yayinlari.

Kirkgoz, Y. (2007). Language Planning and Implementation in Turkish Primary Schools. Current Issues in Language Planning, 8(2), 174-191

Kramsch, C. (1997). The priviledge of the nonnative speaker. PMLA, 112(3), 359-369

Lahdesmaki, S. (2004). Oppikirja tutkijan kasissa. In T. Nevalainen, M. Rissanen \& I. Taavitsainen (Eds.), Englannin aika: Elavan kielen kartoitusta (pp. 529-554). Helsinki: WSOY.

Lessard Clouston, M. (1997). Towards an Understanding of Culture in L2/FL Education. Studies in English, 25, 131-150.

Litz, R. A. D. (2002). Textbook evaluation and ELT management: A South Korean Case Study. Asian EFL Journal, 5-53

Matsumoto, Y. (2011). Successful ELF communications and implications for ELT: sequential analysis of ELF pronunciation negotiation strategies. Modern Language Journal, 95(1), 97-114.

McKay, S. L. (2003). Teaching English as an international language. ELT Journal, 57(2), 139148.

McKay, S. L. (2011). English as an international lingua franca pedagogy. In Handbook of research in second language teaching and learning (pp. 140-157). Routledge.

Newton, J. (2016). Teaching English for intercultural spoken communication. In H. P. Widodo \& W. Renandya (Eds.), English language teaching today: Building a closer link between theory and practice (pp. 161-178). Berlin, Germany: Springer.

Nguyen, M. T. T. (2011). Learning to communicate in a globalized world: to what extent do school textbooks facilitate the development of intercultural pragmatic competence? RELC Journal, 42(1), 17-30

Nguyen, M. T. T. (2015). An Evaluation of the Textbook English 6: A case study from secondary schools in the Mekong Delta Provinces of Vietnam. Unpublished PhD thesis submitted to the University of Sheffield, the UK.

Phillipson, R. (1992). Realities and myths of linguistic imperialism. Journal of Multilingual and Multicultural Development, 18(3), 238-248.

Sifakis, N. C. \& Bayyurt, Y. (2018). ELF-aware teaching, learning and teacher development. In Jennifer Jenkins, Will Baker \& Martin Dewey (Eds.). The Routledge Handbook of English as a Lingua Franca (pp. 456-467). London: Routledge.

Stufflebeam, D. L. (2000). Guidelines for developing evaluation checklists: The checklists development checklist (CDC).Kalamazoo, MI: Center for Evaluation, Western Michigan University.

Sener, S. (2014). Turkish ELT students' willingness to communicate in English. ELT Research Journal, 3, 91-109.

Vanha, L. (2017). Teachers' perspectives on the role of textbooks in English language learning and teachingin Finland. Unpublished Master's Thesis. University of Oulu, Finland.

Yilmaz, H. \& Aydin, S. (2015). A brief review of literature on EFL teachers' perceptions of course books. International Journal of Technical Research and Applications, Special Issue 30. 110-114. 


\section{Biographical notes:}

Cihat Atar works in Department of English Language Teaching, Faculty of Education at Sakarya University. Cihat does research in Conversation Analysis, technology/web for pedagogy and English language teacher training. He had his BA degree (ELT) from Boğaziçi University in 2009 and he earned his MA (TESOL and Applied Linguistics) and PhD (Educational and Applied Linguistics) degrees from the University of Newcastle upon Tyne, the UK in 2012 and 2016 respectively.

Cahit Erdem currently works as an Assistant Professor in the Faculty of Education at AfyonKocatepe University, Turkey. He received his B.A. in English Language Teaching department at Bogazici University, Turkey (2009) and his Ph.D. in Curriculum and Instruction at Anadolu University, Turkey (2018). He has published several articles on Media Literacy, Teacher Education, Foreign Language Teaching and Technology, Education of Refugee Students, Curriculum Literacy, and Internationalization of Higher Education. 